\title{
OPTIMALISASI UNSUR LIVE SHOOT DAN MOTION GRAPHIC UNTUK PROMOSI DIGITAL LEMBAGA PAUD
}

\author{
Aldilla yulandina ${ }^{(1)}$, Condra antoni ${ }^{(2)}$, dan Ardiman firmanda ${ }^{(3)}$ \\ Jurusan Teknik Informatika, Politeknik Negeri Batam \\ Jl.Ahmad Yani, Batam Centre, Batam 2946I, Indonesia \\ Email: ( I) dilnarasyid@gmail.com, (2)_condra@polibatam.ac.id, (3) ardiman@polibatam.ac.id
}

\begin{abstract}
Presentation of information for educational institutions is one of the most important means to introduce the institutions to the public. Raudhatul Athfal (RA) Ar-Rasyid Tanjungpinang needs media that can promote and provide information about the institution, because the number of registrants is decreasing during current years. This research was conducted with the creation of the institution's profile video that applies elements of live shoot and motion graphics to easily convey information in short duration videos, and to make the profile video look interesting. The stage of making a profile video is starting from taking pictures directly (live shoot), editing to rendering process. Based on the process of designing, implementation, testing and discussion, it can be concluded that this research has been able to produce a profile video that can be used as a promotional mean for attracting new students in 2017/2018 at RA Ar-Rasyid Tanjungpinang. The result shows that $77 \%$ of 98 applicants have been informed through video profiles distributed with Videotron.
\end{abstract}

Keywords : Educational institutions, Profile Video, Live Shoot, Motion Graphics, Videotron

\section{PENDAHULUAN}

Video profil merupakan salah satu media yang efektif dalam mempromosikan perusahaan, lembaga pendidikan, produk, hingga promosi untuk potensi daerah (Yuliana, 2013). TK Islam RA Ar-Rasyid Kota Tanjungpinang, Provinsi Kepulauan Riau saat ini membutuhkan media video yang dapat mempromosikan serta memberikan informasi tentang lembaga pendidikan tersebut kepada masyarakat kota Tanjungpinang, dikarenakan media promosi sebelumnya hanya menggunakan brosur dan spanduk. Lembaga pendidikan tersebut terakreditasi B (baik). Namun, berdasarkan data yang penulis dapatkan dari pihak Sekolah, tiga tahun belakangan ini jumlah wali murid (orang tua) yang mendaftarkan anaknya di sekolah ini menurun. Berdasarkan hasil wawancara, menurut pihak sekolah, penurunan jumlah pendaftar ini dapat mempengaruhi kinerja dan potensi sekolah di tahun-tahun pelajaran yang akan datang. Pihak sekolah juga berharap agar sasaran jumlah pendaftar pada tahun pelajaran selanjutnya tidak menurun dari jumlah pendaftar tahun 2016/2017 yang berjumlah 93 orang, bahkan diharapkan dapat melebihi dari jumlah tahun sebelumnya. Berdasarkan informasi yang penulis dapatkan melalui wawancara dengan Ibu Syari'ah selaku kepala sekolah RA Ar-Rasyid Tanjungpinang, sekolah yang sudah didirikan sejak tahun 1994 ini setiap tahunnya membuka jadwal pendaftaran murid baru dimulai dari tanggal 1 Mei sampai dengan 16 Mei. Untuk sarana promosi, sekolah ini menggunakan media konvensional yaitu dengan pembagian 
brosur dan spanduk. Strategi promosi dan informasi tersebut dirasa belum optimal karena jangkauan penyebaran kurang luas dan informasi yang tersampaikan terbatas. Dengan adanya perkembangan teknologi informasi yang sangat besar saat ini, lembaga pendidikan dituntut untuk mengembangkan strategi promosi dan informasi berbasis multimedia.

Menurut Vaughan (2004), multimedia merupakan kombinasi teks, seni, suara, gambar, animasi, dan video yang disampaikan menggunakan komputer atau dimanipulasi secara digital dan dapat disampaikan dan/atau dikontrol secara interaktif. Beberapa teknik multimedia diantaranya adalah live shoot dan motion graphic. Live shoot dapat diartikan sebagai teknik pengambilan gambar bergerak secara langsung dimana dalam pengerjaannya diperlukan editing untuk menyempurnakan hasil shooting. Live shoot adalah serangkaian rekaman tentang orangorang, atau makhluk hidup lainnya, paling tidak ada satu atau lebih karakter yang diperankan oleh seseorang atau beberapa orang yang menciptakan suatu adegan yang dramatis, yang dipadu dengan kejadian dramatis lainnya dan disusun pada suatu proses editing (Jatmiko, 2014).

Menurut pendapat Michael Bentacourt, Ahli Teori Perfilman dalam artikelnya yang berjudul "The Origins of Motion Graphics", menyatakan bahwa motion graphic adalah media yang menggunakan rekaman video dan/atau teknologi animasi untuk menciptakan ilusi gerak dan biasanya digabungkan dengan audio untuk digunakan dalam sebuah output multimedia. Motion graphic biasanya ditampilkan melalui media elektronik (Sukarno, 2014).

Banyaknya media elektronik yang dapat digunakan untuk menyampaikan pesan dalam video diantaranya adalah Videotron (digital billboard). Media tersebut dianggap cukup efektif dikarenakan dapat dilihat secara langsung dan berkala oleh masyarakat, khususnya masyarakat kota Tanjungpinang.

Berdasarkan uraian tersebut, maka yang menjadi tujuan penelitian ini adalah menghasilkan video profil yang dapat digunakan sebagai media promosi dan informasi lembaga pendidikan serta mengetahui keberhasilan distribusi video profil melalui media Videotron.

Penelitian sebelumya yang berjudul "Pembuatan Video Profil Sekolah Menengah Atas 2 Surakarta" (Yulianna, 2013) menghasilkan sebuah video profil lembaga pendidikan yang membahas tentang profil Sekolah Menengah Atas 2 Surakarta. Fokus pembahasannya adalah pembuatan video profil yang menggunakan metode Produksi, Pra-produksi dan Pasca produksi, serta media penyimpanan yang digunakan yaitu DVD. Kemudian penelitian yang lain adalah "Perancangan dan Pembuatan Iklan Roti Kondang Jaya Madiun Menggunakan Teknik Live Shoot Dan Motion Graphics" (Norrislam, 2015). Penelitian tersebut menghasilkan sebuah video iklan yang menggunakan teknik live shoot dan motion graphic dengan metode analisis SWOT. Selanjutnya penelitian yang lain adalah "Pengembangan Media Sosialisasi Etika Kampus Dalam Bentuk Animasi 2D” penelitian tersebut menghasilkan film animasi 2D yang menggunakan metode pengembangan multimedia Luther-Sutopo (Sembiring, 2015). Dari penelitian-penelitian tersebut penulis membuat video profil lembaga pendidikan RA Ar-Rasyid Tanjungpinang yang dapat digunakan sebagai media promosi dan informasi dengan menerapkan teknik live shoot dan motion graphic. Serta menggunakan metode Luther-Sutopo sebagai metode penelitian. Maka yang menjadi tujuan penelitian ini adalah menghasilkan video profil yang dapat digunakan sebagai media promosi dan informasi lembaga pendidikan serta mengetahui keberhasilan distribusi video profil melalui media Videotron.

2 | Aldilla Yulandina et al. : Optimalisasi Unsur Live Shoot Dan Motion Graphic... 


\section{Pendidikan Usia Dini}

Pendidikan anak usia dini (early education) adalah fondasi bagi pendidikan selanjutnya. Ibarat bangunan, jika pondasinya rapuh, maka seluruh bangunan akan mudah roboh. Seperti dikatakan filsuf dan pendidik John Locke, “Anak-anak usia dini bagai kertas putih bersih". Dengan demikian, pembentukan yang paling tepat seorang manusia, sebenarnya pada usia dini 3-5 tahun. Sayangnya, pendidikan anak usia dini sering dipandang sebelah mata. Tidak sebagaimana jenjang pendidikan selanjutnya, terutama pendidikan tinggi, banyak pikiran dan investasi diarahkan kesana. Di negara-negara maju, pendidikan anak usia dini justru sangat diperhatikan. Tidak hanya orang tua dan pendidik, pemerintahpun menginvestasikan seluruh daya upaya memajukan pendidikan anak usia dini karena dianggap sebagai basis bagi pendidikan selanjutnya. (Wasik et. al, 2006).

\section{LANDASAN TEORI}

\section{Jalur Penyelenggara PAUD}

Berdasarkan Undang-undang RI No. 20 Tahun 2003 tentang Sistem Pendidikan Nasional (SISDIKNAS) yang dimaksud dengan Pendidikan Anak Usia Dini adalah suatu upaya pembinaan yang ditujukan kepada anak sejak lahir sampai dengan usia enam tahun yang dilakukan melalui pemberian rangsangan pendidikan untuk membantu pertumbuhan dan perkembangan jasmani dan rohani agar anak memiliki kesiapan dalam memasuki pendidikan lebih lanjut.

Nurani (2016) menjelaskan penyelenggaraan pendidikan bagi anak usia dini dapat dilakukan dalam bentuk formal, nonformal dan informal. Pendidikan di jalur informal dilakukan oleh keluarga atau lingkungan. Terdapat berbagai lembaga PAUD yang selama ini telah dikenal oleh masyarakat luas, di antaranya:

1. Taman Kanak-kanak (TK) dan Raudhatul Athfal (RA)

TK dan RA adalah salah satu bentuk satuan pendidikan bagi anak usia dini pada jalur pendidikan formal yang menyelenggarakan program pendidikan bagi anak usia empat tahun sampai enam tahun.

2. Kelompok Bermain

Kelompok bermain adalah salah satu bentuk PAUD pada jalur pendidikan non formal yang menyelenggarakan program pendidikan sekaligus program kesejahteraan bagi anak usia 2 sampai dengan 4 tahun.

3. Taman Penitipan Anak

TPA adalah salah satu bentuk PAUD jalur pendidikan non-formal yang menyelenggarakan program pendidikan sekaligus pengasuhan dan kesejahteraan anak sejak lahir sampai dengan usia 6 tahun. Atau dengan kata lain, Taman Penitipan Anak (TPA) adalah wahana pendidikan dan pembinaan kesejahteraan anak yang berfungsi sebagai pengganti keluarga untuk jangka waktu tertentu selama orang tuanya berhalangan atau tidak memiliki waktu yang cukup dalam mengasuh anaknya karena bekerja atau sebab lain (Depdiknas Program Belajar TPA, Jakarta 2001)

\section{Multimedia}

Suyanto (2003) mengatakan multimedia menjadi penting karena dapat digunakan sebagai alat persaingan. Disamping itu, pada abad ke-21 ini multimedia menjadi suatu keterampilan dasar yang sama pentingnya dengan membaca. Sesungguhnya, multimediapun mengubah hakikat membaca itu sendiri. Multimedia menjadikan kegiatan membaca itu dinamis dengan memberi dimensi baru pada kata-kata. Apalagi dalam hal penyampaian 
makna, kata-kata dalam aplikasi multimedia bisa menjadi pemicu yang dapat digunakan untuk memperluas cakupan teks ketika memeriksa suatu topik tertentu. Multimedia tidak hanya dengan menyediakan lebih banyak teks, melainkan juga dengan menghidupkan teks yang disertai bunyi, gambar, musik, animasi, dan video.

\section{Video Profil}

Sebuah instansi pemerintahan, perusahaan, maupun lembaga pendidikan dalam berinteraksi dengan masyarakat tentunya dituntut mampu membangun citra diri yang sesuai sehingga dapat menarik simpati masyarakat. Keberhasilan memperkenalkan diri (public relation) merupakan langkah awal dari kesuksesan selanjutnya. Untuk kebutuhan tersebut sekaligus sarana promosi, instansi pemerintahan, perusahaan ataupun lembaga pendidikan membutuhkan sebuah sarana yang digunakan sebagai company profile (profil perusahaan). Sarana ini dapat berupa file presentasi, media kertas, atau video dengan sajian informasi yang lengkap, padat, menarik, dan jelas. Instansi pemerintahan, perusahaan, sekolah, LSM, atau lembaga lainnya kadang diharuskan untuk menyampaikan perkembangan produktivitas kerja atau proses secara periodik kepada publik. Untuk keperluan tersebut dapat digunakan media informasi yang tidak hanya dalam format cetak, tetapi biasa dilengkapi dengan video (Wahana Komputer, 2008).

\section{Type of shot dalam Live Shoot}

Live shoot adalah serangkaian rekaman tentang orang-orang, atau makhluk hidup lainnya, paling tidak ada satu atau lebih karakter yang diperankan oleh seseorang atau beberapa orang yang menciptakan suatu adegan yang dramatis, yang dipadu dengan kejadian dramatis lainnya dan disusun pada suatu proses editing (Jatmiko, 2014). Santoso (2013) menjelaskan Type Of Shot bisa juga disebut pembingkaian gambar. Di layar, kita bisa melihat bermacam-macam tampilan type of shot, misalnya gambar terlihat sangat luas: dari tepi lautan sampai kaki gunung dan awan biru. Di scene yang lain, hanya terlihat wajah seseorang yang sedang berbicara dalam satu layar penuh, atau gambar seseorang yang terlihat dari ujung kepala sampai dada saja. Berbagai tipe lebar gambar inilah yang disebut dengan type of shot. Terdapat beberapa variasi type of shot yaitu:

1. Extreme Long Shot (ELS)

2. Long Shot (LS)

3. Medium Long Shot (MLS)

4. Medium Shot (MS)

5. Close Up $(\mathrm{CU})$

6. Big Close Up (BCU)

7. Extreme Close Up (ECU)

\section{Motion Graphic}

Wardhani (2014) dalam jurnalnya menjelaskan motion graphics adalah grafis yang menggunakan video dan/atau animasi untuk menciptakan ilusi gerak ataupun transformasi. Graphic design telah berubah dari statis publishing dengan memanfaatkan teknologi komunikasi termasuk film, animasi, media interaktif, dan environmental design.

Seperti yang dijelaskan dalam buku "Video Editing \& Video Production" mayoritas industri film, video, dan televisi menggunakan Adobe After Effects untuk membuat animasi bumper pergantian acara televisi yang 
belakangan banyak menghiasi layar kaca, salah satunya yaitu program acara musik "Breakout" yang menggunakan motion graphic untuk membuat animasi bumper pembukaan acara tersebut. Contoh bumper dapat dilihat pada gambar 1 .

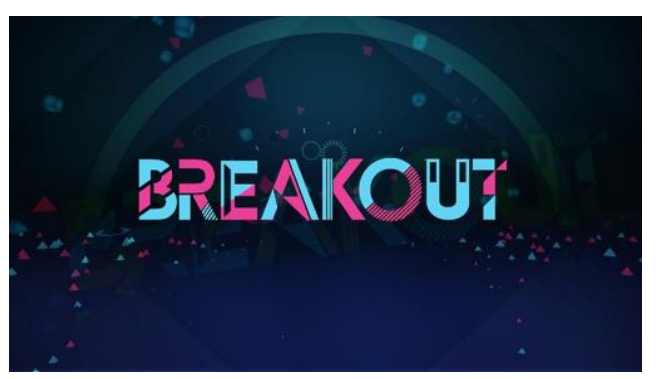

Gambar 1 Animasi Bumper Program Acara Musik "Breakout"

\section{Media Promosi Outdoor}

Terdapat beberapa media promosi outdoor yang umum digunakan diataranya yaitu Videotron (digital billboard). Digital billboard merupakan billboard dengan teknologi terbaru berupa penggunaan teknologi digital dalam penyampaian pesannya. Digital billboard atau yang biasa disebut Videotron kini mulai digunakan di kota-kota besar. Salah satu bentuknya adalah media iklan berupa televisi raksasa (giant television). Keunggulan dari penggunaan billboard ini yaitu tampilan gambar bergerak yang dapat dilihat secara nyata (Supriyanto, 2008)

\section{Software Editing Video}

1. Adobe Premier Pro

Adobe Premier Pro adalah software editing video yang memiliki fitur lengkap dan telah popular digunakan di masyarakat secara luas. Karena masih dalam satu kelompok dengan Adobe, Adobe Premier Pro memiliki kesamaan interface dengan Adobe After Effects dan Adobe Photoshop. (Wahana Komputer, 2008).

2. Adobe After Effects

Adobe After Effects adalah software motion graphic dan visual effect yang dibuat oleh Adobe System Inc. Software ini merupakan aplikasi animasi dan visual effect yang banyak digunakan profesional di bidang digital video. Selain untuk menghasilkan visual effect saat membuat film, Adobe After Effects juga banyak digunakan oleh pada video kreatif untuk membuat karya video dengan durasi yang pendek, misalnya untuk membuat spot iklan dan spot acara (Gora, 2004).

\section{Skala Likert}

Skala Likert digunakan untuk mengatur sikap, pendapat, dan persepsi seseorang atau sekelompok orang tentang fenomena sosial. Dalam penelitian, fenomena sosial ini telah ditetapkan secara spesifik oleh peneliti, yang selanjutnya disebut variabel penelitian (Sugiyono, 2014). Untuk keperluan analisis kuantitatif, maka jawaban tersebut dapat diberi skor, misalnya: 


$\begin{array}{lll}\text { Kode } & \text { Pernyataan } & \text { Skor } \\ \text { SS } & \text { Sangat Setuju } & 5 \\ \text { ST } & \text { Setuju } & 4 \\ \text { RG } & \text { Ragu-ragu/Netral } & 3 \\ \text { TS } & \text { Tidak Setuju } & 2 \\ \text { STS } & \text { Sangat Tidak Setuju } & 1\end{array}$

Instrumen penelitian yang menggunakan skala Likert dapat dibuat dalam bentuk checklist atau pilihan ganda. Untuk mendapatkan hasil presentase, harus diketahui terlebih dahulu skor tertinggi (X) dan angka terendah (Y) untuk item penilaian sebagai berikut:

\begin{tabular}{|l|}
\hline $\mathrm{Y}=$ Skor tertinggi likert $\mathrm{x}$ jumlah responden (Angka Tertinggi 5) \\
\hline $\mathrm{X}=$ Skor tertinggi likert $\mathrm{x}$ jumlah responden (Angka Terendah 1) \\
\hline
\end{tabular}

Penilaian interpretasi responden adalah hasil nilai yang dihasilkan dengan menggunakan rumus Indeks \%.

Rumus Indeks \% $=$ Total Skor $/ \mathrm{Y}$ x 100

Dari data yang didapat, kemudian diolah dengan cara mengkalikan setiap poin jawaban dengan bobot yang sudah ditentukan dalam tabel skor nilai. Kemudian hasil dari jawaban seluruh responden dapat ditentukan dari keterangan pada tabel persentase nilai (Arikunto, 2002) yang dapat dilihat pada tabel 1

Tabel 1 Tabel Persentase Nilai (Arikunto, 2002)

\begin{tabular}{|l|l|}
\hline Jawaban & Keterangan \\
\hline $0 \%-19,99 \%$ & Sangat Tidak Setuju \\
\hline $20 \%-39,99 \%$ & Tidak Setuju \\
\hline $40 \%-59,99 \%$ & Ragu-ragu/Netral \\
\hline $60 \%-79,99 \%$ & Setuju \\
\hline $80 \%-100 \%$ & Sangat Setuju \\
\hline
\end{tabular}

\section{Skala Guttman}

Skala Guttman digunakan apabila ingin mendapatkan jawaban yang tegas terhadap suatu permasalahan. Skala pengukuran tipe ini akan mendapat jawaban yang tegas, yaitu ya-tidak; benar-salah; pernah-tidak pernah; positifnegatif; dan lain-lain. Data yang diperoleh dapat berupa data interval atau rasio dikotomi (dua alternatif) jika pada skala Likert terdapat interval "sangat setuju" sampai "sangat tidak setuju" maka pada skala Guttman hanya ada dua interval yaitu "setuju" atau "tidak setuju" (Sugiyono, 2015).

6 | Aldilla Yulandina et al. : Optimalisasi Unsur Live Shoot Dan Motion Graphic... 
Rangkuti (2015) menjelaskan tujuan skala ini adalah untuk memperoleh ukuran gabungan yang bersifat unidimentional (hanya mengukur satu dimensi saja). Hasil tanggapan berdasarkan skala Guttman akan dihitung koefisien reprodusibilitas dan koefisien skalabilitas terlebih dahulu. Koefisien repordusibilitas (Kr) adalah jumlah kesalahan yang menyimpang dari pola idealnya. Biasanya Kr sama dengan atau lebih besar dari 0,90 dianggap cukup baik untuk dipergunakan. Koefisien skalabilitas (Ks) untuk menilai apakah penyimpangan tersebut masih dalam batas-batas yang dapat ditolerir. Biasanya Ks sama dengan atau lebih besar dari 0,60 dianggap cukup baik untuk dipergunakan. Rumus perhitungan $\mathrm{Kr}$ dan Ks dapat dilihat pada tabel 2.

Tabel 2 Rumus Kr dan Ks (Rangkuti, 2015)

\begin{tabular}{|l|l|}
\hline Koefisien Responsibilitas (Kr) & $\begin{array}{l}\mathrm{Kr}=1 \text { - e (error) } / \mathrm{n} \\
\text { Dimana } \mathrm{n}=\text { jum.responden } \mathrm{x} \text { jum.pertanyaan }\end{array}$ \\
\hline Koefisien Skalabilitas (Ks) & $\begin{array}{l}\mathrm{Ks}=1-\mathrm{e} \text { (error) } / \mathrm{k} \\
\text { dimana } \mathrm{k}=0,5 \mathrm{x}(\mathrm{n}-\text { jumlah jawaban YA) }\end{array}$ \\
\hline
\end{tabular}

Untuk proses penarikan kesimpulan teknik analisis data yang digunakan adalah teknik hitung analisis deskriptif, untuk mendeskripsikan variabel penelitian dalam pengukuran. Menurut Nazir (2014) analisis deskriptif adalah pencarian fakta dengan interpretasi yang tepat. Adapun teknik statistik yang digunakan untuk penarikan kesimpulan adalah perhitungan persentase (Bungin, 2010). Rumus perhitungan persentase dapat dilihat pada tabel 3.

Tabel 3 Rumus Perhitungan Persentase (Bungin, 2010)

\begin{tabular}{|lll|}
\hline $\mathrm{P}=\mathrm{f} / \mathrm{n} \times 100 \%$ \\
\hline dimana: & \\
$\mathrm{P} \quad=$ Persentase & \\
$\mathrm{f}$ & $=$ frekuensi jawaban YA \\
$\mathrm{n}$ & $=\quad$ jumlah responden $\mathrm{x}$ jumlah \\
& pertanyaan) \\
\hline
\end{tabular}

Selanjunya hasil persentase yang diperoleh di terjemahkan ke dalam tabel persentase predikat keberhasilan (Agip, 2009) yang dapat dilihat pada tabel 4.

Tabel 4 Persentase Predikat Keberhasilan (Agip, 2009)

\begin{tabular}{|l|l|}
\hline Persentase & Predikat Keberhasilan \\
\hline $86 \%-100 \%$ & Sangat tinggi \\
\hline $71 \%-85 \%$ & Tinggi \\
\hline $56 \%-70 \%$ & Sedang \\
\hline $41 \%-55 \%$ & Rendah \\
\hline$<40 \%$ & Sangat Rendah \\
\hline
\end{tabular}




\section{ANALISIS DAN PERANCANGAN}

Metodologi perancangan video profil dalam penelitian mengacu pada metode pengembangan Multimedia Versi Luther-Sutopo yang dikemukakan oleh Sutopo (2003), yang terdiri dari enam tahapan yaitu: concept, design, material collecting, assembly, testing, dan distribution. Pada bab ini dijelaskan tentang analisis dan perancangan yaitu tahap concept sampai dengan material collecting. Proses perancangan metodologi Luther-Sutopo dapat dilihat pada gambar 2 .

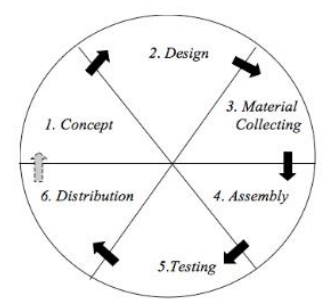

Gambar 2 Metodologi Pengembangan Multimedia Luther-Sutopo (Binanto, 2010).

\section{Concept}

Secara umum, konsep pada video profil RA Ar-Rasyid Tanjungpinang ini menerapkan teknik live shoot dan motion graphic untuk mempermudah penyampaian informasi dalam video profil. Dimana fasilitas, kegiatan belajar dan prestasi dapat dilihat secara nyata serta mempermudah penyampaian informasi penerimaan murid baru tahun pelajaran 2017/2018 di dalam video profil. Pada tahap ini beberapa hal yang perlu diperhatikan antara lain:

1. Video profil ini ditujukan kepada masyarakat, khususnya masyarakat kota Tanjungpinang dengan tujuan dapat memberikan informasi serta menarik minat masyarakat terhadap lembaga pendidikan RA Ar-Rasyid Tanjungpinang.

2. Konsep yang digunakan adalah penggabungan antara live shoot dan motion graphic dalam sebuah video profil lembaga pendidikan.

3. Video profil lembaga pendidikan ini tidak menampilkan tentang sejarah lembaga pendidikan, tetapi akan mengulas tentang fasilitas sekolah, kegiatan belajar, prestasi dan informasi mengenai penerimaan murid baru tahun pelajaran 2017/2018 di RA Ar-Rasyid Tanjungpinang.

4. Hasil akhir dari penelitian ini berupa video profil dengan durasi 30 detik.

5. Video profil ditampilkan menggunakan media Videotron (digital billboard)

6. Target jumlah pendaftar diharapkan dapat mencapai jumlah yang sama ( 93 pendaftar), atau dapat melebihi jumlah pendaftar dari tahun 2016//2017.

\section{Pengguna dan Sasaran Video Profil}

Pengguna video profil adalah pihak lembaga pendidikan RA Ar-Rasyid Tanjungpinang. Video profil ini digunakan untuk memberikan informasi kepada sasaran video profil, yaitu masyarakat Kota Tanjungpinang. Video profil ini diharapkan mampu memberikan informasi tentang lembaga pendidikan RA Ar-Rasyid Tanjungpinang, sehingga masyarakat dapat mengetahui fasilitas, kegiatan belajar mengajar, prestasi, serta informasi penerimaan murid baru di RA Ar-Rasyid Tanjungpinang Untuk mengetahui apakah pembuatan video profil ini telah sesuai dengan tujuannya, maka penulis akan menggunakan kuesioner (angket) untuk melihat tingkat kepuasan pengguna terhadap hasil pembuatan video profil. Serta untuk mengetahui apakah video profil yang telah didistribusikan 
melalui videotron dapat membantu memberikan informasi penerimaan murid baru di RA Ar-Rasyid Tanjungpinang kepada masyarakat kota Tanjungpinang, maka penulis melakukan penyebaran kuesioner terhadap pendaftar di RA Ar-Rasyid Tanjungpinang saat pendaftaran berlangsung.

\section{Design}

Design dalam pembuatan video profil dengan menerapkan unsur live shoot dan motion graphic, penulis menggunakan skenario dan storyboard untuk merancang alur proses informasi secara detail dan terstruktur sehingga mempermudah pengerjaan pada tahap assembly.

\section{Skenario}

\section{BUMPER MOTION GRAPHIC OPENING LOGO}

MENAMPILKAN SCENE PEMBUKA DENGAN GAMBAR LOGO RA AR-RASYID TANJUNGPINANG

CUT TO:

\section{EXT. GEDUNG SEKOLAH}

ELS, CAMERA BERGERAK MEMPERLIHATKAN GEDUNG SEKOLAH DAN HALAMAN BERMAIN memperlihatkan gedung sekolah dan halaman bermain

CUT TO:

\section{INT. RUANG KELAS BELAJAR}

LS, KAMERA BERGERAK MEMPERLIHATKAN SUASANA BELAJAR DI KELAS

Beberapa anak terlihat serius belajar dan mewarnai buku pelajaran di kelas.

\section{INT. RUANG KELAS BELAJAR - 2}

MCU, KAMERA MEMPERLIHATKAN SEORANG ANAK SEDANG MENGERJAKAN TUGAS DI KELAS.

seorang anak terlihat sedang serius belajar dengan tekun

CUT TO:

\section{INT. PRESTASI}

CU, KAMERA MENAMPILKAN BEBERAPA PRESTASI YANG DITERIMA OLEH SEKOLAH

memperlihatkan beberapa piala prestasi yang terdapat di ruang kepala sekolah

CUT TO:

\section{INT. RUANG KELAS MENGAJI}

MS, KAMERA BERGERAK MEMPERLIHATKAN SUASANA MENGAJI DI KELAS

beberapa anak terlihat serius menyimak Al-Qu'ran dan Iqra' serta didampingi oleh guru saat mengaji di kelas.

CUT TO: 


\section{INT. RUANG KELAS MENGAJI - 2}

MCU, KAMERA MEMPERLIHATKAN SEORANG ANAK SEDANG MENGAJI DI BIMBING OLEH GURU.

terlihat seorang anak sedang membaca Al-Qur'an didampingi oleh guru

CUT TO:

\section{INT. MUSHOLLA}

LS, KAMERA BERGERAK MEMPERLIHATKAN ANAK-ANAK SHOLAT BERJAMAAH DI MUSHOLLA.

terlihat beberapa anak sedang khusyuk dalam melaksanakan praktik sholat berjama'ah.

CUT TO:

\section{BUMPER MOTION GRAPHIC INFORMASI}

MENAMPILKAN SCENE INFORMASI PENERIMAAN MURID BARU DI RAAR-RASYID TANJUNGPINANG

\section{Storyboard}

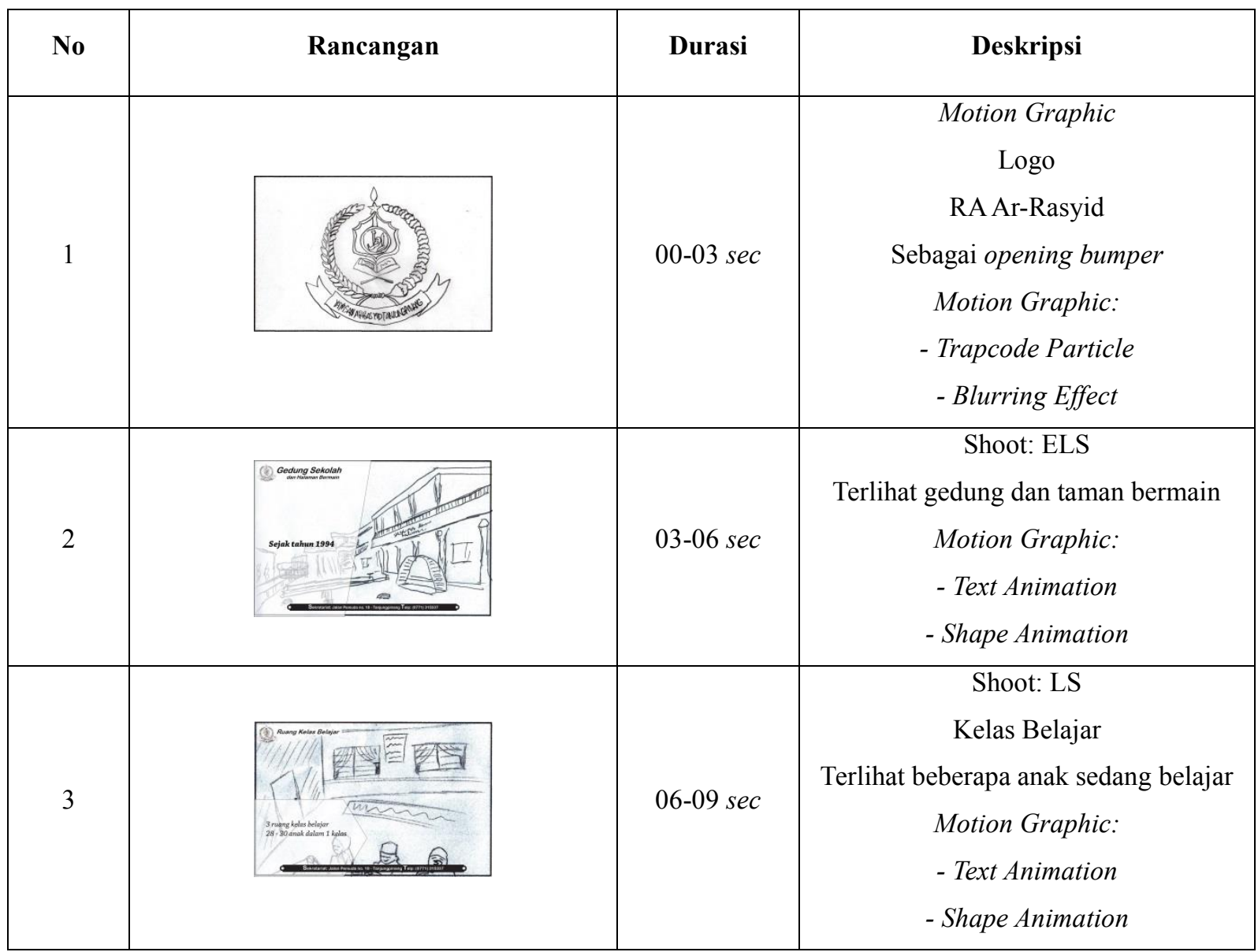

10 | Aldilla Yulandina et al. : Optimalisasi Unsur Live Shoot Dan Motion Graphic... 


\begin{tabular}{|c|c|c|c|}
\hline 4 & & $09-12 \mathrm{sec}$ & $\begin{array}{c}\text { Shoot: MCU } \\
\text { Seorang Anak Sedang Mengerjakan } \\
\text { Tugas Dari Guru Di Kelas } \\
\text { Motion Graphic: } \\
\text { - Text Animation } \\
\text { - Shape Animation }\end{array}$ \\
\hline 5 & 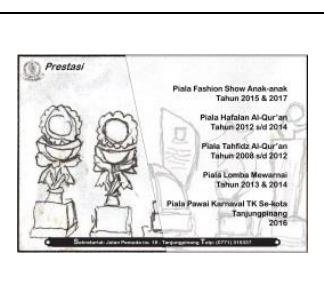 & $12-15 \mathrm{sec}$ & $\begin{array}{c}\text { Shoot: CU } \\
\text { Prestasi } \\
\text { Motion Graphic: } \\
\text { - Text Animation } \\
\text { - Shape Animation }\end{array}$ \\
\hline 6 & a & $15-18 \mathrm{sec}$ & $\begin{array}{c}\text { Shoot: MS } \\
\text { Terlihat seorang guru dan beberapa } \\
\text { murid sedang mengaji bersama } \\
\text { Motion Graphic: } \\
\text { - Text Effect } \\
\text { - Shape Annimaton }\end{array}$ \\
\hline 7 & & $18-21 \mathrm{sec}$ & $\begin{array}{c}\text { Shoot: } \mathrm{MCU} \\
\text { Seorang anak sedang membaca Al- } \\
\text { Qur'an } \\
\text { Motion Graphic: } \\
\text { - Text Effect } \\
\text { - Shape Annimaton }\end{array}$ \\
\hline 8 & Ed हो? & $21-24 \mathrm{sec}$ & $\begin{array}{c}\text { Shoot: LS } \\
\text { Anak-anak sedang melaksanakan } \\
\text { sholat berjamaah di musholla } \\
\text { Motion Graphic: } \\
\text { - Text Animation } \\
\text { - Shape Animation }\end{array}$ \\
\hline 9 & 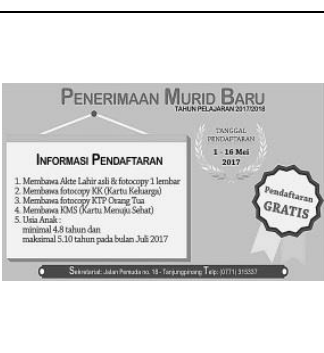 & $24-30 \mathrm{sec}$ & $\begin{array}{c}\text { Informasi penerimaan murid baru } \\
\text { Motion Graphic: } \\
\text { - Text Animation } \\
\text { - Shape Animation } \\
\text { - Trapcode Particle } \\
\text { - Blurring Effect }\end{array}$ \\
\hline
\end{tabular}

\section{Material Collecting}

Pada tahap ini, pengumpulan bahan terkait penerapan unsur live shoot dan motion graphic, penulis dapatkan melalui referensi buku, internet, dan tanya jawab dengan orang yang lebih ahli. serta pengumpulan data mengenai RA Ar-Rasyid Tanjungpinang, penulis dapatkan dari pihak-pihak terkait lembaga pendidikan tersebut 


\section{Spesifikasi Kebutuhan Hardware}

Berikut adalah kebutuhan perangkat keras (hardware) yang menunjang pembuatan video profil, mulai dari pengambilan gambar hingga editing video.

1. Kamera DLSR

2. Kartu memori $16 \mathrm{~GB}$

3. Tripod dan Monopod

4. Komputer Multimedia

a. Intel ${ }^{\circledR}$ Core $^{\mathrm{TM}} \mathrm{i} 3$

b. RAM 4GB

c. Resolusi layar $1920 \times 1080$

d. Hardisk

e. Speaker

\section{Spesifikasi Kebutuhan Software}

1. Adobe Premier Pro CS6

Adobe Premier Pro merupakan aplikasi utama yang akan digunakan untuk editing dalam pengolahan video. Aplikasi ini digunakan untuk memilih atau menyunting (editing) kumpulan gambar dari hasil shooting (live shoot).

2. Adobe After Effects CS6

Adobe After Effects merupakan aplikasi pendukung yang digunakan untuk menambahkan unsur motion graphic pada video, mulai dari pengaturan gerakan tipografi, gerakan logo, dan kalimat informasi yang disampaikan dalam video profil.

\section{HASIL DAN PEMBAHASAN}

\section{Assembly}

Tahap assembly (pembuatan) adalah tahap dimana semua objek atau bahan multimedia dibuat dimulai dari tahap shooting, editing, hingga rendering video. Lokasi dan waktu dalam proses pembuatan video profil yang berlangsung di dalam lingkungan sekolah RA Ar-Rasyid Tanjungpinang. Pembuatan video profil didasarkan pada tahap pembuatan storyboard, dan struktur navigasi yang berasal dari tahap design.

Proses pertama yang dilakukan pada tahap pembuatan (assembly) adalah pengambilan gambar (shooting) baik gambar bergerak maupun gambar diam, kemudian setelah semua hasil shooting telah terkumpul, maka tahap selanjutnya yaitu melakukan proses editing hingga me-render (rendering) hasil scene video. Deskripsi tahapan assembly dijelaskan dalam tabel 5.

12 | Aldilla Yulandina et al. : Optimalisasi Unsur Live Shoot Dan Motion Graphic... 
Tabel 5 Tempat dan Waktu Proses Assembly

\begin{tabular}{|c|c|c|c|}
\hline Tahapan & Deskripsi & Tempat & Waktu \\
\hline \multirow{5}{*}{ Shooting } & $\begin{array}{l}\text { Pengambilan gambar pada gedung dan halaman } \\
\text { sekolah }\end{array}$ & $\begin{array}{l}\text { Halaman Sekolah RA Ar- } \\
\text { Rasyid Tanjungpinang }\end{array}$ & 1 hari \\
\hline & $\begin{array}{l}\text { Pengambilan gambar beberapa piala prestasi murid di } \\
\text { sekolah }\end{array}$ & $\begin{array}{l}\text { Ruang kepala sekolah RA } \\
\text { Ar-Rasyid Tanjungpinang }\end{array}$ & 1 hari \\
\hline & Pengambilan gambar ruang kelas belajar & \multirow{2}{*}{$\begin{array}{l}\text { Ruang kelas di RA Ar-Rasyid } \\
\text { Tanjungpinang }\end{array}$} & 1 hari \\
\hline & Pengambilan gambar ruang kelas mengaji & & 2 hari \\
\hline & Pengambilan gambar ruang musholla & $\begin{array}{l}\text { Musholla di RA Ar-Rasyid } \\
\text { Tanjungpinang }\end{array}$ & 1 hari \\
\hline \multirow{3}{*}{ Editing } & Pemilihan hasil shoot pada video profil & - & 4 hari \\
\hline & $\begin{array}{l}\text { Pemilihan, record narasi dan setting backsound video } \\
\text { profil }\end{array}$ & - & 1 hari \\
\hline & $\begin{array}{l}\text { Penggabungan logo dan teks untuk motion graphic } \\
\text { serta penggabungan motion graphic dengan scene } \\
\text { video }\end{array}$ & - & 7 hari \\
\hline Rendering & $\begin{array}{l}\text { File output yang dihasilkan yaitu video dalam } \\
\text { format .mp4 dan berdurasi } 30 \text { detik }\end{array}$ & - & 1 hari \\
\hline
\end{tabular}

\section{Testing}

Testing (pengujian) dilakukan setelah selesai tahap pembuatan (assembly) dengan menjalankan aplikasi/program dan dilihat apakah ada kesalahan atau tidak (Binanto, 2010). Tahap pertama pada tahap ini disebut tahap pengujian alpha (alpha test) yang pengujiannya dilakukan oleh pembuat atau lingkungan pembuatnya sediri. Setelah lolos dari pengujian alpha, selanjutnya dilakukan pengujian beta yang melibatkan pengguna akhir. Adapun pengujian (testing) yang dilakukan setelah tahap assembly adalah sebagai berikut:

1. Pengujian Alpa (Alpha Test)

Pada tahap alpha test, pengujian yang dilakukan berdasarkan hasil rancangan storyboard (Binanto, 2010) serta didukung dengan validasi yang disetujui oleh pembimbing (lingkungan pembuat) Pengujian dilakukan pada saat hasil pengerjaan video profil sudah sesuai dengan perancangan storyboard yang berasal dari tahap design. Hasil pengujian alpha tes dapat dilihat pada tabel 6.

Tabel 6 Hasil Pengujian Alpha Test

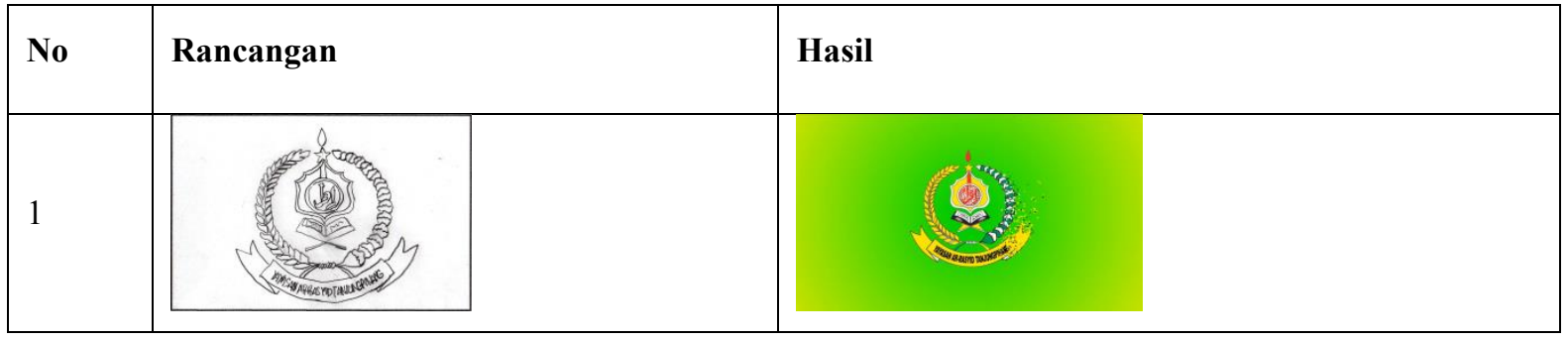




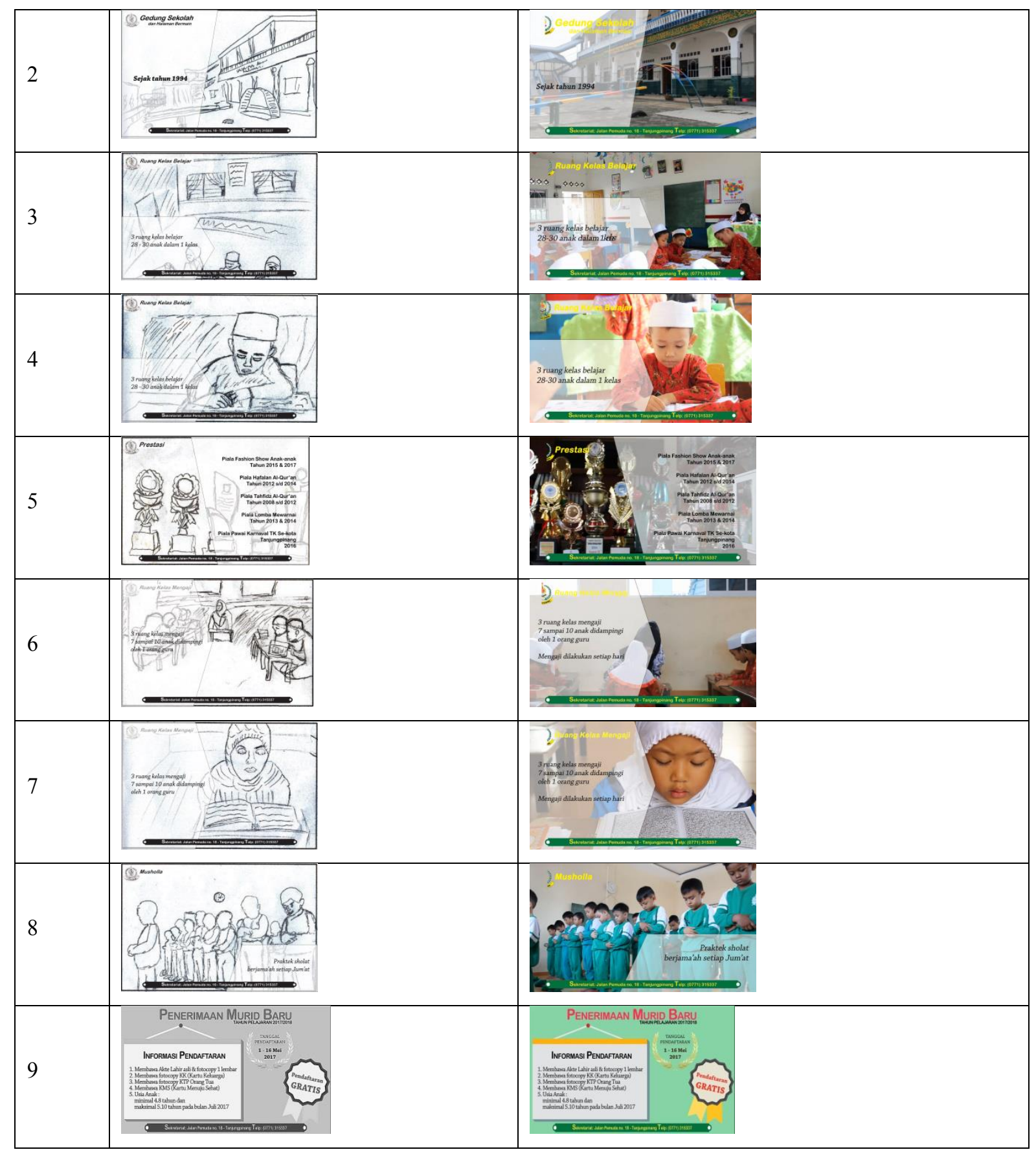

\section{Pengujian Beta (Beta Test)}

Binanto (2010) menyatakan setelah lolos dari pengujian alpha, dilanjutkan dengan pengujian beta (beta test). Pada tahap beta test, pengujian dilakukan terhadap pengguna video profil, yaitu pihak lembaga pendidikan. Dimana pihak pengguna video profil ini adalah pihak RA Ar-Rasyid Tanjungpinang yang berjumlah 16 orang responden yang terdiri dari kepala sekolah beserta guru-guru RA Ar-Rasyid Tanjungpinang. Pengujian dilakukan diruang lingkup lembaga pendidikan RA Ar-Rasyid Tanjungpinang. Pengujian dilakukan dengan menggunakan skala Likert. Hasil tanggapan pengguna dapat dilihat pada tabel 7.

14 | Aldilla Yulandina et al. : Optimalisasi Unsur Live Shoot Dan Motion Graphic... 
Tabel 7 Hasil Tanggapan Pengguna

\begin{tabular}{|l|l|l|l|l|l|l|}
\hline No & Pernyataan & SS & ST & RG & TS & STS \\
\hline 1 & Durasi video profil singkat dan padat & 8 & 7 & 1 & 0 & 0 \\
\hline 2 & Informasi yang disampaikan mudah dipahami & 9 & 5 & 1 & 1 & 0 \\
\hline 3 & Informasi yang ditampilkan dalam video profil lengkap & 4 & 6 & 5 & 1 & 0 \\
\hline 4 & Tampilan video profil menarik & 11 & 5 & 0 & 0 & 0 \\
\hline
\end{tabular}

Dari data yang telah didapatkan kemudian diolah dengan cara mengkalikan setiap poin jawaban dengan bobot yang sudah ditentukan dengan tabel bobot nilai untuk mendapatkan hasil indeks persentase (Arikunto, 2002). Berdasarkan hasil persentase, maka dapat dirangkum dalam grafik yang dapat dilihat pada gambar 3 .

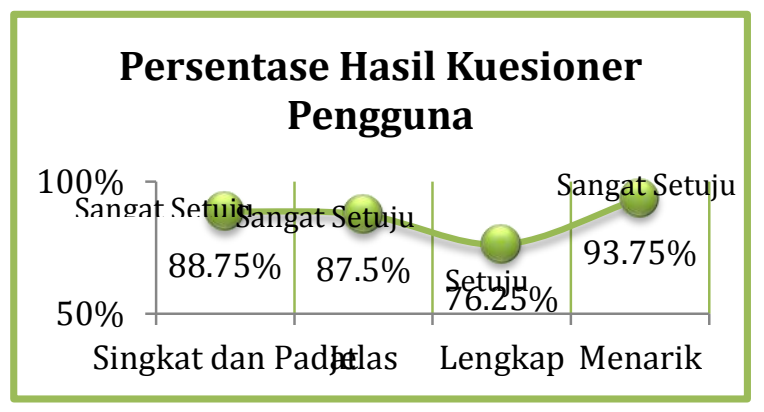

Gambar 3 Grafik Hasil Kuesioner Pengguna

Berdasarkan grafik diatas, dapat dilihat sebanyak $88.75 \%$ pengguna sangat setuju dengan durasi penayangan video profil yang cukup singkat dan padat, kemudian $87.5 \%$ pengguna sangat setuju dengan informasi yang disampaikan di dalam video profil mudah dipahami, 76,25\% pengguna setuju bahwa informasi yang di sampaikan di dalam video profil cukup lengkap, serta $93.75 \%$ pengguna video profil sangat setuju bahwa tampilan video profil terlihat menarik. Dengan demikian maka dapat disimpulkan pembuatan video profil dengan menerapkan unsur live shoot dan motion graphic dapat memberikan informasi yang jelas dan mudah dipahami dalam video profil yang berdurasi cukup singkat, serta pergerakan tipografi, shape effect dan logo yang menggunakan motion graphic dalam video profil dapat membantu penyampaian informasi serta membuat video profil tidak monoton dan terlihat menarik.

\section{Distribusi}

Pada tahap ini, video profil dengan durasi 30 detik dan format MP4 ini didistribusikan melalui Videotron (digital billboard) yang terletak di pusat kota Tanjungpinang. Waktu penayangan video profil pada videotron berlangsung dari bulan April hingga bulan Mei 2017. Tampilan video yang telah didistribusikan menggunakan videotron dapat dilihat pada gambar 4 


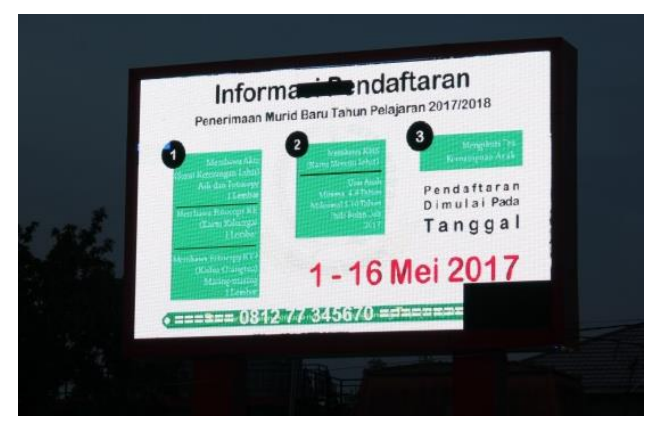

\section{Gambar 4 Tampilan Video Profil Dalam Videotron}

Setelah distribusi video profil dilakukan, penulis mengumpulkan data jumlah pendaftar di RA Ar-Rasyid Tanjungpinang, untuk mengetahui apakah jumlah pendaftar pada tahun 2017 bertambah dari tahun sebelumnya. Berdasarkan data yang penulis dapatkan dari pihak lembaga pendidikan RA Ar-Rasyid Tanjungpinang, terhitung sejak tanggal 1 mei sampai dengan 16 mei 2017, terdapat 98 wali murid yang mendaftar di RA Ar-Rasyid Tanjungpinang. Serta untuk mengetahui keberhasilan distribusi video profil melalui media videotron, maka penulis mencari persentase dari jumlah pendaftar yang mengetahui informasi penerimaan murid baru di RA ArRasyid Tanjungpinang dengan menggunakan kuesioner. Penulis memberikan sejumlah pertanyaan yang berhubungan dengan distribusi video profil RA Ar-Rasyid Tanjungpinang. Pemberian kuesioner penulis lakukan pada saat pendaftaran berlangsung dan dilakukan diruang lingkup lembaga pendidikan RA Ar-Rasyid Tanjungpinang. Perhitungan kuesioner menggunakan skala Guttman dan perhitungan Persentase untuk memudahkan dalam mengambil kesimpulan. Hasil tanggapan pendaftar dapat dilihat pada tabel 8.

Tabel 8 Hasil Tanggapan Kuesioner Pendaftar

\begin{tabular}{|l|l|l|l|}
\hline \multirow{2}{*}{ No } & Pertanyaan & \multicolumn{2}{|l|}{ Jawaban } \\
\cline { 2 - 4 } & & $\begin{array}{l}\text { Pernah/ } \\
\text { YA }\end{array}$ & $\begin{array}{l}\text { Belum } \\
\text { Pernah/ Tidak }\end{array}$ \\
\hline 1 & $\begin{array}{l}\text { Apakah Bapak/Ibu pernah melihat media iklan digital yang disebut } \\
\text { Videotron? }\end{array}$ & 96 & 2 \\
\hline 2 & $\begin{array}{l}\text { Apakah Bapak/Ibu pernah melihat tayangan video iklan atau tayangan video } \\
\text { pariwisata melalui media Videotron? }\end{array}$ & 95 & 3 \\
\hline 3 & $\begin{array}{l}\text { Apakah Bapak/Ibu pernah melihat tayangan Video Profil RA Ar-Rasyid di } \\
\text { media Videotron? }\end{array}$ & 61 & 37 \\
\hline 4 & $\begin{array}{l}\text { Jika pernah melihat tayangan video profil tersebut, apakah Bapak/Ibu } \\
\text { berminat mendaftar di RA Ar-Rasyid setelah melihat tayangan tersebut? }\end{array}$ & 49 & 49 \\
\hline
\end{tabular}

Dari data yang telah didapatkan kemudian diolah dengan cara menghitung Koefisien Responsibilitas (Kr) dan Koefisien Skalabilitas (Ks) terlebih dahulu, untuk mengetahui apakah hasil kuesioner layak digunakan. Perhitungan $\mathrm{Kr}$ dan Ks dapat dilihat pada tabel 9.

16 | Aldilla Yulandina et al. : Optimalisasi Unsur Live Shoot Dan Motion Graphic... 
Tabel 9 Rumus Perhitungan Kr dan Ks (Rangkuti, 2015)

\begin{tabular}{|l|l|}
\hline \multirow{2}{*}{ Koefisien Responsibilitas (Kr) } & $\begin{array}{r}\mathrm{Kr}=1-\mathrm{e} \text { (error) } / \mathrm{n} \\
\text { Dimana } \mathrm{n}=\text { jumlah responden } \mathrm{x} \text { jumlah pertanyaan } \\
=1-2 /(98 \times 4) \\
=0.99(>0.90)\end{array}$ \\
\hline Koefisien Skalabilitas (Ks) & $\begin{array}{r}\mathrm{Ks}=1-\mathrm{e}(\text { error }) / \mathrm{k} \\
\text { dimana } \mathrm{k}=0,5 \times(\mathrm{n}-\text { jumlah jawaban YA) } \\
=1-2 / 0,5 \times(392-301) \\
=0.96(>0.60)\end{array}$ \\
\hline
\end{tabular}

Menurut pendapat Rangkuti (2015) skala yang memiliki nilai $\mathrm{Kr}>0.90$ dan skala yang memiliki nilai $\mathrm{Ks}>0.60$, maka skala tersebut dianggap layak dan baik digunakan dalam penelitian. Data yang diperoleh dengan perhitungan $\mathrm{Kr}$ dan $\mathrm{Ks}$ masih bersifat kuantitatif sehingga perlu diolah untuk proses penarikan kesimpulan. Adapun teknik statistik yang digunakan dalam penarikan kesimpulan adalah perhitungan persentase (Bungin, 2010) yang dapat dilihat pada tabel 10 .

Tabel 10 Rumus Perhitungan Persentase (Bungin, 2010)

$$
\begin{aligned}
\mathrm{P} & =\mathrm{f} / \mathrm{n} \times 100 \% \\
\mathrm{P} & =301 /(98 \times 4) \times 100 \% \\
& =76.78 \%(77 \%)
\end{aligned}
$$

Berdasarkan hasil perhitungan tersebut, maka dapat disimpulkan 77\% dari 98 pendaftar mengetahui informasi pendaftaran murid baru di RA Ar-Rasyid Tanjungpinang, melalui video profil yang didistribusikan melalui videotron. Adapun persentase 77\% ini dikategorikan tinggi berdasarkan tabel predikat keberhasilan dalam penyampaian informasi pendaftaran murid baru di RA Ar-Rasyid Tanjungpinang, serta jumlah pendaftar tahun pelajaran 2017/2018 meningkat menjadi 98 pendaftar dibandingkan jumlah pendaftar tahun pelajaran 2016/2017 yang berjumlah 93 orang. Alma dan Hurriyati (2008) menjelaskan indikator keberhasilan pemasaran jasa pendidikan dari segi kuantitas yaitu pendaftar dapat memenuhi atau bahkan melebihi target jumlah yang ditentukan. Berdasarkan hasil kuesioner dan teori tersebut maka dapat disimpulkan distribusi video profil sebagai media promosi dan informasi yang didistribusikan melalui media videotron, telah berhasil dalam meningkatkan jumlah pendaftar saat pendaftaran murid baru tahun pelajaran 2017/2018 di RA Ar-Rasyid Tanjungpinang. 


\section{KESIMPULAN DAN SARAN}

\section{Kesimpulan}

Berdasarkan perancangan, implementasi, pengujian, dan pembahasan maka dapat disimpulkan bahwa:

1. Metode Luther Sutopo yang terdiri dari 6 tahap yaitu concept, design, material collecting, assembly, testing dan distribution, maka telah dapat menghasilkan video profil lembaga pendidikan RA Ar-Rasyid Tanjungpinang.

2. Teknik live shoot dan motion graphic merupakan solusi yang tepat dalam penyampaian informasi pada video profil dengan durasi yang cukup singkat. Hal tersebut dapat dilihat berdasarkan hasil pengujian alpa yang telah di validasi (oleh pembimbing) serta hasil pengujian beta dari pihak lembaga pendidikan RA Ar-Rasyid Tanjungpinang (pengguna) dimana sebanyak $87 \%$ pihak lembaga pendidikan sangat setuju informasi yang disampaikan di dalam video profil RA Ar-Rasyid Tanjungpinang tersebut mudah di pahami serta tampilan video profil tidak monoton dan terlihat menarik.

3. Video profil yang didistribusikan melalui media videotron telah berhasil dalam membantu meningkatkan jumlah pendaftar. Hal tersebut dapat disimpulkan berdasarkan jumlah pendaftar pada tahun 2017 meningkat menjadi 98 pendaftar dibandingkan dengan jumlah pendaftar pada tahun 2016 yang berjumlah 93 orang. Serta berdasarkan hasil tanggapan kuesioner pendaftar, sebanyak 77\% dari 98 pendaftar (kategori tinggi) mengetahui informasi pendaftaran murid baru di RA Ar-Rasyid Tanjungpinang, melalui video profil yang didistribusikan melalui media videotron.

\section{Saran}

Setelah dilakukan pengujian serta evaluasi terhadap video profil RA Ar-Rasyid Tanjungpinang ini maka penulis berharap video profil ini dikembangkan dengan saran-saran pengembangan sebagai berikut:

1. Video profil selanjutnya dapat didistribusikan di media sosial agar penyebaran informasi dalam video profil dapat tersebar luas serta durasi penayangan video profil tidak terbatas.

2. Video profil RA Ar-Rasyid Tanjungpinang yang selanjutnya didistribusikan melalui media sosial, dapat di kembangkan dengan kata sambutan kepala sekolah serta lebih banyak menampilkan kegiatan murid-murid dan para guru didalam video profil nantinya dan didukung dengan kalimat-kalimat informasi di dalam tampilannya, agar informasi yang disampaikan didalam video profil lebih bisa mengenalkan lembaga pendidikan RA Ar-Rasyid Tanjungpinang serta memberikan informasi secara detail kepada masyarakat.

\section{DAFTAR PUSTAKA}

Undang-Undang Republik Indonesia Nomor 20 Tahun 2003. (2003). Jakarta: Sisdiknas.

Kamus Besar Bahasa Indonesia. (2016). Jakarta: Badan Bahasa.

Agip, Z. (2009). Penelitian Tindakan Kelas Untuk Guru SD, SLB, dan TK. Bandung: Yrama Widya.

Alma, B., \& Hurriyati, R. (2008). Manajemen Corporate dan Strategi Pemasaran Jasa Pendidikan. Bandung: Alfabeta.

Arikunto, S. (2002). Prosedur Penelitian Suatu Pendekatan Praktek. Jakarta: PT. Rineka Cipta.

Binanto, Iwan. (2010). Multimedia Digital, Dasar Teori dan Pengembangannya. Yogyakarta: Penerbit Andi.

Brata, V. B. (2007). Videografi dan Sinematografi Praktis. Jakarta: Elex Media.

Bungin, B. (2010). Metode Penelitian Kuantitatif. Jakarta: Prenada Media Group.

18 | Aldilla Yulandina et al. : Optimalisasi Unsur Live Shoot Dan Motion Graphic... 
Gora, W. (2004). Motion Graphic dan Visual Effect Menggunakan Adobe After Effect. Yogyakarta: Andi.

Jatmiko, A. (2014). Pengimplementasian Teknik Animasi Motion Tracking Dan Live Shoot Camera Pada Video Klip The Everyday Band. Naskah Publikasi, Yogyakarta: Amikom

Komputer, W. (2008). Video Editing dan Video Production. Jakarta: Elex Media Komputindo.

Nazir, M. (2014). Metode Penelitian. Bogor: Ghalia Indonesia.

Norrislam. (2015). Perancangan dan Pembuatan Iklan Roti Kondang Jaya Madiun Menggunakan Teknik Live Shoot Dan Motion Graphics. Yogyakarta: Amikom.

Nurani, Y. (2016). Konsep Dasar Pendidikan Anak Usia Dini. Jakarta: Indeks.

Santoso, E. J. (2013). Bikin Video Dengan Kamera DLSR. Jakarta: Media Kita.

Seefeldt, C., \& Wasik, B. A. (2006). Pendidikan Anak Usia Dini: Menyiapkan anak usia tiga, empat, dan lima tahun masuk sekolah. (D. S, Ed., \& P. Nasar, Trans.) New Jersey: Pearson Education, Inc.

Sembiring, E. B. (2015). Pengembangan Media Sosialisasi Etika Kampus Dalam Bentuk Animasi 2D. Jurnal Teknomatika, Batam: Politeknik Negeri Batam

Sugiyono. (2008). Metode Penelitian Pendidikan: Pendekatan Kuantitatif, Kualitatif, dan R\&D. Bandung: Alfabeta.

Sukarno, I. S. (2014). Perancangan Motion Graphic Ilustratif Mengenai Majapahit Untuk Pemuda-Pemudi. Jurnal Tingkat Sarjana Bidang Senirupa dan Desain, Bandung: Institut Teknologi Bandung

Supriyanto, S. A. (2008). Meraih Untung Dari Spanduk Hingga Billboard. Yogyakarta: Pustaka Grhatama.

Supriyono, R. (2010). Desain Komunikasi Visual: Teori dan Aplikasi. Yogyakarta: Andi.

Suyanto, M. (2003). Multimedia: Alat Untuk Meningkatkan Keunggulan Bersaing. Yogyakarta: Andi.

Vaughan, T. (2004). Multimedia: Making It Work. Edisi ke-6. New York: McGraw-Hill Companies.

Waloeya, Y. J. (2012). Seri Belajar Kilat Adobe After Effects CS5. Yogyakarta: ANDI.

Widjaja, C. (2008). Kamera Video Editing - Adobe Premier Pro. Bandung: Widjaja.

Yulianna, R. (2013). Pembuatan Video Profil Sekolah Menengah Atas 2 Surakarta. Vol 2 No 1 - Maret 2013 ISSN: 2302-1136 - seruniid.unsa.ac.id, Surakarta: Universitas Negeri Surakarta 